\title{
KONSEP KETATANEGARAAN PAKISTAN PERSPEKTIF FIQH SIYASAH
}

\author{
Muhammad Faqih \\ Universitas Islam Negeri Sunan Ampel Surabaya, Indonesia \\ faqih2896@gmail.com \\ Ellyda Retpitasari \\ Institut Agama Islam Tribakti Kediri, Indonesia \\ ellyda@iai-tribakti.ac.id
}

\begin{abstract}
The purpose of this research is to find out the pakistani constitutional system in terms of tate institutions and fiqh siyasah. The method used is library reaserch with two approaches, namely conseptual approach and historical approach. The results of the research of the concept of Pakistani state regulation fiqh siyasah perspective in the era: (1) In general the state of Pakistan can be said to be a country with a weak democracies system, this is motivated by the unstable system of government and constitutional system since Pakistan's independence in 1947. In addition, the cause of the instability of the country is the violence and feud between three social forces, namely Hindus who are the majority in India, indian Muslims who are minorities and The British as invaders with modern political and technological forces that developed in the country of pakistan. (2) The establishment of the Indian Muslim League, Muhammad Ali Jinnah initiated the theory of "two nations" and formally presented the demands of a Muslim


homeland separate from India. In a 1940 resolution the Muslim League conveyed the establishment of an independent and fully sovereign Pakistani state. (3) On 15 August 1947 Pakistan was born as a fully sovereign state for Indian Muslims. Islam and Muslims in Pakistan have made a real contribution in the development of civilization in the Islamic world. Pakistan is a country that takes Islam as a source of law has become a phenomenon in the study of the relationship of the country and religion in Islam.

Keywords: Pakistan's constitutional system, democracy, fiqh siyasah

\section{PENDAHULUAN}

Islami Jumburiyya e-Pakistan (Islamic Republic of Pakistan) merupakan nama panjang dari Negara Pakistan, Negara ini berawal dari sebuah Negara pecahan India dengan luas wilayah mencapai $803.940 \mathrm{~km} 2$ dengan geografis terbentang di Asia bagian selatan. Pada tahun 2016 Pakistan memiliki jumlah penduduk 201.275.591 jiwa dengan mayoritas beragama Islam dengan presentase sebesar 97\% selebihnya Kristen, Hindu, dan Parsian, dengan adanya jumlah mayoritas beragama Islam yang banyak, Pakistan menjadi Negara dengan bangsa muslim terbesar kedua di Dunia. ${ }^{1}$. Pakistan sebagai sebuah Negara Islam, berdiri tidak lepas dari situasi dan kondisi yang melatar belakangi, diantaranya: situasi geografis, social keagamaan dan politik. Pakistan merupakan Negara pertama di dunia yang diakui secara formal sebagai republic Islam. "The constitusion of Islamic Republic of Pakistan" yaitu Negara demokrasi berdasarkan prinsip yang berkeadilan ${ }^{2}$.

Ideologi Pakistan dengan Islam sebagai bangsa (islam as nation) tentunya mempengaruhi basis legitimasi, sumber identitas kultural dan factor yang membedakan dari dunia asing seperti non-muslim³. Pemerintahan berturut-turut juga telah menggunakan Islam secara instrumental sebagai alat untuk memperkuat negara-bangsa dan untuk memperkuat basis kekuatan negara. Dibuat pada tahun 1947 sebagai

\footnotetext{
${ }^{1}$ Syaifudin Zuhri, "Reformulasi Hukum Perceraian di Pakistan," Jurnal Law and Justice 1, no. 1 (t.t.): 41.

2 Syam Firdaus, Pemikiran Politik Barat: Sejarah Filsafat Ideologi, dan pengarubnya terhadap Dunia ke-3, cetakan ke 3 (Jakarta: Bumi Aksara, 2007), 311-12.

3 Idzam Fautanu, "Pakistan sebagai Locus Pertarungan Ideologis antara Islam dan Sekularisme (Sebuah Tinjuan Sejarah)," Madrasalah Malam Reboan (MMR), November 2017, 1.

116 Muhammad Faqih \& Ellyda Retpitasari - Konsep Ketatanearaan Pakistan
} 
tanah air merdeka bagi Muslim di sub-benua India, menurut visi pendirinya, Muhammad Ali Jinnah, dimana Pakistan dimaksudkan untuk menjadi negara demokrasi Muslim modern daripada negara teokratis. Namun, segera setelah kematian Jinnah pada tahun 1948, para pemimpin politik dan agama mulai melobi agar Pakistan dideklarasikan sebagai negara Islam, sebagian untuk melawan kebangkitan nasionalisme di Pakistan Timur. Islam, menurut pendapat mereka, adalah perekat yang akan menyatukan Pakistan. Tujuan ini sebagian terwujud ketika Objectives Resolution disahkan pada tahun 1949. Resolusi yang diadopsi oleh Majelis Konstituante merupakan langkah besar pertama dalam penyusunan konstitusi untuk Pakistan. Ia menyatakan bahwa konstitusi masa depan Pakistan tidak akan mencontoh pola Eropa, tetapi pada ideologi dan keyakinan demokratis Islam. Misalnya, beberapa prinsipnya akan mengakui bahwa: a) sementara kedaulatan universal ada di tangan Allah, Negara Pakistan dipercayakan untuk menjalankannya dalam batasbatas tertentu; dan b) Muslim akan 'dimampukan untuk mengatur kehidupan mereka dalam lingkungan individu dan kolektif sesuai dengan ajaran dan persyaratan Islam sebagaimana diatur dalam Alquran dan Sunnah'. Setelah sembilan tahun upaya, proses penyusunan konstitusi berakhir dengan sukses dan Pakistan memproklamasikan republik Islam.

Untuk sejarah politik Pakistan menjadi salah satu kegagalan untuk membangun institusi politik yang tahan lama dan kredibel. Ketidakstabilan politik ini juga terlihat dari kegagalan upaya Pakistan untuk mendirikan lembaga yang berfungsi atau memberikan dampak pada masyarakat serta adanya pemilihan umum menjadi pokok hal yang penting. Dalam lima puluh lima tahun, Pakistan telah memiliki tiga konstitusi - dibuat pada tahun 1956, 1962 dan pada tahun 1973 - dan pada tahun 1985 ketika Zia ul Haq secara mendasar mengubah konstitusi dengan memperkenalkan Amandemen Kedelapan yang menetapkan eksekutif yang didominasi presiden. Pemilu nasional dalam beberapa tahun terakhir diadakan pada tahun 1985, 1988,1990, 1993, dan 1997 dan 2008 tetapit idak ada pemerintah Pakistan terpilih yang sejauh ini menggantikan yang lain - semuanya telah digulingkan oleh militer atau diberhentikan oleh perintah presiden ${ }^{4}$.

Para pemimpin Pakistan selalu menghadapi masalah mendasar pembangunan bangsa dan negara. Kelahiran traumatis Pakistan, menimbulkan dampak perpecahannya antara Timur dan Barat, pemisahan berdarah Bangladesh, dan perbatasannya yang tidak aman, semuanya telah menantang gagasan Pakistan sebagai negara-bangsa yang

4 Wajahat Qazi, "Democratisation and Transitional Justice Cluster "Country Case Study: Pakistan," International Journal of Education and Research 1, no. 1 (Januari 2013): 1. 
bersatu dengan batas-batas tetap dan identitas bersama. Hal ini semakin ditantang oleh sejarah otonom dan identitas etnis yang kuat dari masingmasing empat provinsi di Pakistan. Provinsi-provinsi sebenarnya telah disusun di sekitar empat kelompok etnis utama: Punjabi, Sindhis, Baluchi dan Pashtun, yang masing-masing dicirikan oleh berbagai subkelompok berdasarkan divisi etno-linguistik, pekerjaan dan kasta. Di Baluchistan dan Sindh, khususnya, sejarah dan identitas yang berbeda ini telah dimanfaatkan oleh gerakan nasionalis dan separatis yang secara langsung menantang pemerintah federal.

Para pemimpin Pakistan berturut-turut telah melihat membangkitkan nasionalisme dan membangun identitas nasional bersama sebagai tugas utama. Untuk melakukannya, mereka mengandalkan dua strategi utama: menjamin keamanan negara dan mempromosikan Islam sebagai faktor pemersatu. Pertama-tama, ancaman terhadap keamanan negara yang ditimbulkan oleh aktor eksternal (yaitu India) dan aktor internal (misalnya separatis Baluchi) telah membantu memperkuat tangan militer dan melegitimasi periode pemerintahan mereka. Posisi dominan militer dalam sistem pemerintahan negara sebagian merupakan hasil dari konfrontasi dengan India atas Kashmir segera setelah pemisahan ${ }^{5}$. Menelaah terkait ketatanegaraan negara Pakistan tentunya sangat banyak hal yang perlu dikaji, akan tetapi penulis dalam hal ini fokus perihal Sejarah Sosial Ketatanegaraan Pakistan, Bentuk Negara, Konstitusi, Penerapan Trias Politik, dan Hak-Hak Warga Negara. Dalam penyusunan karya ilmiah ini, penulis mengidentifikasi masalah pembahasan ini yang diantaranya membahas tentang Bagaimana Sejarah Sosial Ketatanegaraan Pakistan, Bentuk Negara, Konstitusi, Penerapan Trias Politik, dan Hak-Hak Warga Negara.

\section{METODOLOGI}

Penelitian ini menggunakan qualitative research dengan menggunakan bahan sekunder yakni literatur tentang konsep ketananegaraan di Pakistan. ${ }^{6}$ Dalam penelitian ini menggunakan metode kepustakaan dan

\footnotetext{
${ }^{5}$ Marco Mezzera, dan Safiya Aftab, "Democratisation and Transitional Justice Cluster "Country Case Study: Pakistan.," Pakistan State-Society Analysis, Initiative for Peacebuilding, 2008, 17-18.

6 Muchlisin, "Pandemi Covid 19 Sebagai Alasan impeacment Presiden Perspektif Hukum Tata Negara," Tafaqqub: Jurnal Penelitian dan Kajian Keislaman 8, no. 2 (2020): 166.

118 Muhammad Faqih \& Ellyda Retpitasari - Konsep Ketatanearaan Pakistan
} 
kesejarahan, penulis mengacu pada teknik dan metode yang dikemukakan oleh Nugroho Notosusanto ${ }^{7}$ yaitu:

1. Heuristik berasal dari bahasa Yunani yaitu "beuriskein" yang bermakna menemukan atau mencari serta mengumpulkan jejakjejak kesejarahan. Heuristik juga bisa didapat dari sumber primer dan sekunder.

Nugroho Notosusanto memberikan definisi bahwa sumber primer suatu sumber yang keterangannya didapat secara langsung oleh yang menyaksikan peristiwa itu ${ }^{8}$. Dalam penelitian ini penulis tidak bisa menemukan sumber primer dikarenakan keterbatasan ruang dan waktu serta keterbatasan kemampuan penulis.

Adapun sumber sekunder yang dijelaskan Nugroho Notosusanto yaitu keterangan yang diperoleh pengarangnya dari orang lain atau sumber lain.

2. Historiografi yaitu suatu tahap akhir dalam penulisan sejarah. Historiografi merupakan cara penulisan, pemaparan atau pelaporan hasil penelitian sejarah yang dilakukan penulis. Dan kegiatan pengumpulan jejak-jejak sejarah atau masa lampau dapat dilakukan dengan heuristik literature.

\section{HASIL DAN PEMBAHASAN}

Siyasah Islamiyah merupakan siyasah (politik) yang berbasis maslahah berasal dari al-Qur'an dan Hadis Nabi, bukan yang berasal dari kepentingan individu, kelompok maupun golongan tertentu. Diketahui secara etimologi (Bahasa) fiqh merupakan pemahaman. Adapun fiqh ditinjau dalam terminology (istilah) merupakan pengetahuan tentang hukum syar'I mengenai amal perbuatan (praktis) yang diperoleh dari dalil tafshili (terinci) yaitu hukum-hukum khusus yang diambil dari al-Qur'an dan as-Sunnah. Maka dengan demikian siyasah berasal dari kata sasa. Kata ini dalam kamus Lisan al-Arab diartikan mengatur, mengurus, memerintah, membuat kebijaksanaan, pemerintahan dan politik. Ditinjau secara terminologis dalam kitab Lisan al-Arab, kata siyasah ialah mengatur atau memimpin sesuatu dengan cara yang membawa kepada kemaslahatan. Dari kedua penjelasan tentang fiqh dan siyasah, maka fiqh siyasah diartikan sebagai ilmu yang mempelajari hal-ihwal urusan umat dan negara dalam berbagai bentuk hukum, pengaturan dan kebijaksanaan yang dibuat oleh pemangku kebijakan dengan dasar ajaran syariat untuk

\footnotetext{
7 Nugroho Notosusanto, Norma-Norma dalam Pemikiran dan penulisan Sejarah (Jakarta: Departemen Pertahanan dan Keamanan, 1988), 35.

${ }^{8}$ Notosusanto, 19.
} 
mewujudkan kemaslahatan umat. ${ }^{9}$ Perlu diketahui bahwa fiqh siyasah menjadi sub-kajian dalam fiqh muamalah yang perlu memperhatikan hakikat dan substansinya, bukan sekedar format an sich..$^{10}$

Membahas perihal Negara Pakistan sebagai Negara bekas jajahan Inggris, namun dapat menjadi Negara dengan Ideologi dan Konstitusi berlandaskan Islam memiliki sejarah dan polemik beragam pembahasan yang penulis telaah sebagai berikut:

\section{Sejarah Sosial Ketatanegaraan Pakistan}

Negara Pakistan dengan Ibukota Islamabad merdeka pada tanggal 14 Agustus 1947. Negara ini menjadi bekas jajahan koloni Inggris yang menduduki Asia Selatan sejak tahun 1498. Pada masa penjajahan Inggris telah terjadi beragam ketegangan dalam system hukum, tepatnya dalam hal kebijakan dan peradilan yang merupakan benturan antara common law dan hukum Islam. System hukum tersebut banyak diberlakukan melalui kebijakan procedural dan peradilan Inggris yang terasa asing bagi umat muslim maupun non-muslim seperti Hindu.

Perumusan Pakistan menjadi sebuah Negara digagas oleh Muhammad Iqbal dalam pidatonya Liga Muslim India di tahun 1930. Rumusan ini direalisasikan oleh Muhammad Ali Jinnah dengan memberikan rancangan tujuan dan visi-misi pembentukan Negara Islam pada Liga Muslim India di Lahore tahun 1940. Berbagai Ulama dari beberapa golongan memberikan masukan akan berdirinya Negara Islam pada Liga Muslim India. Masukan ini terutama pada pemecahan India Muslim menjadi Negara sendiri akan melemahkan kekuatan Islam, sehingga beberapa partai politik agama hanya memberikan dukungan secara samar-samar. Tujuh tahun kemudian, pada tanggal 14 Agustus 1947 Inggris memberikan kedaulatannya pada dewan konstitusi, sejak itulah Pakistan resmi menjadi Negara berdaulat dengan Muhammad Ali Jinnah sebagai gubernur jenderal yang bergelar Quaid-I Azam (Pemimpin besar) ${ }^{11}$.

\section{Bentuk Negara Pakistan}

Pakistan merupakan negara republik parlementer federal. Pada tahun 2018, Partai Pakistan Tehreek-e Insaf (PTI) Memenangkan kursi

\footnotetext{
${ }^{9}$ Wahyu Abdul Jafar, "FIQH SIYASAH DALAM PERSPEKTIF AL-QUR'AN DAN AL-HADIST," AL IMARAH: JURNAL PEMERINTAHAN DAN POLITIK ISLAM 3, No. 1 (1 Juli 2018): 19-20, Https://Doi.Org/10.29300/Imr.V3i1.2140.

10 Muhammad Sofi Mubarok, "Membedah Anatomi Fiqh Siyasah dalam Putusan Mahkamah Konstitusi tentang Presidential Thershold," Tafaqqub: Jurnal Penelitian dan Kajian Keislaman 8, no. 2 (2020): 225.

11 Zuhri, "Reformulasi Hukum Perceraian di Pakistan," 43.

120 Muhammad Faqih \& Ellyda Retpitasari - Konsep Ketatanearaan Pakistan
} 
Majelis Nasional terbanyak dalam pemilihan umum, dan pemimpin PTI, Imran Khan, menjadi perdana menteri. Adapun pengamat independen mencatat peningkatan teknis dalam manjemen KPU Pakistan atas proses pemungutan suara itu sendiri, pengamat, organisasi, masyarakat sipil, dan partai politik menyuarakan keprihatinan tentang campur tangan pra pemilu oleh bandan-badan militer dan inteligen yang menciptakan medan permainan pemilu yang tidak seimbang ${ }^{12}$.

\section{Konstitusi Pakistan}

Konstitusi pertama Negara Pakistan yakni Konstitusi 1956 yang terbangun dengan pengaruh Negara bekas jajahan Inggris, terkait perundang-undangan, model hukum dan model pendidikan. Konsitutsi Pakistan bersifat demokratis namun tetap islami. Pakistan menjadi Negara republic Islam dengan system demokrasi Parlementer model Westminster sehingga dalam konstitusi ini Pakistan disebut sebagai "Republik Islam Pakistan). Adanya perundang-undangan akhirnya memunculkan republic Islam dengan karakter religious hingga tahun 1962 disaat perubahan konstitusi pada masa Presiden Agha Mohammed Yahya Khan dengan menghilangkan nama Islam dalam penyebutan republic Pakistan. Adanya perubahan konstitusi ini membentuk dua lembaga yaitu dewan penas ihat ideology Islam dan Lembaga Pengkajian Islam ${ }^{13}$.

Konstitusi berikutnya yakni Konstitusi 1973 menyatakan bahwa Pakistan sebagai Federal Republic yang dikenal sebagai Republik Islam Pakistan, mengakui perihal Islam sebagai agama negara. Pakistan akan menjadi federation dari empat unit federasi, Punjab, Sindh, NWFP, dan $\mathrm{Ba}$ Iochistan. Konstitusi bersifat parlementer dengan badan legislative bicameral di Pusat yang terdiri dari dua Dewan yakni Majelis Nasional dan Senat. Meskipun konstitusi 1973 telah ditunda selama pemerintah militer pada akhir 1970-an/ awal 1980-an, dan sampai saat ini, telah diubah sebanyak 19 kali, saat ini konstitusi tersebut mengatur negara. Amandemen terbaru terkait konstitusi negara Pakistan disahkan pada April 2010, menghapus sebagian besar perubahan konstitusional yang diperkenalkan selama rezim militer, serta secara resmi mengubah nama Provinsi Perbatasan Barat Laut menjadi Khyber Pakhtunkhwa dan telah memberikan provinsi otonomi yang lebih besar.

12 "Country Reports on Human Rights Practices for 2019, Pakistan 2019 Human Rights Report." (United States Departement of State: Bureau of Democracy, Human Rights and Labor, t.t.).

13 Zuhri, "Reformulasi Hukum Perceraian di Pakistan," 44. 
Berdasarkan konstitusi saat ini, Parlemen dapat membuat undangundang untuk dua provinsi atau lebih dengan persetujuan jika permintaan dibuat oleh provinsi-provinsi tersebut. Jika pemerintah dalam keadaan Darurat di Provinsi mana pun, kekuasaan untuk membuat undang-undang yang disahkan oleh Parlemen selama keadaan darurat, tidak lagi berlaku setelah berakhirnya enam bulan sejak tanggal darurat dicabut. Dalam menjalankan peran konstitusionalnya, DPR juga memiliki tugas penting yang harus dijalankan. Presiden yang merupakan Kepala Negara, dipilih oleh anggota DPR dan Dewan Provinsi. Perdana menteri yang merupakan kepala kabinet dan dimaksudkan untuk membantu dan memberikan nasihat kepada presiden perihal fungsinya ${ }^{14}$.

\section{Penerapan Trias Politika Pakistan \\ Eksekutif}

Konstitusi 1973 menetapkan bahwa Presiden akan menjadi Kepala Negara. Presiden harus bertindak atas nasihat perdana menteri Pakistan, dan dapat diberhentikan atas dasar ketidakmampuan fisik atau mental atau dimakzulkan dengan tuduhan melanggar konstitusi atau pelanggaran berat dengan suara dua pertiga dari anggota parlemen.

Presiden Pakistan dipilih melalui pemungutan suara rahasia melalui Electoral College yang terdiri dari anggota Senat, Majelis Nasional dan Majelis Provinsi. Presiden merupakan Seseorang yang beragama Islam dan berusia tidak kurang dari 45 tahun dan memenuhi syarat untuk dipilih sebagai anggota Majelis Nasional dapat mengikuti pemilihan Presiden. Presiden dipilih untuk masa jabatan 5 tahun dan diberi wewenang untuk mengangkat Jaksa Agung, Hakim, Mahkamah Agung dan Pengadilan Tinggi, serta Komisi Pemilihan dalam Pemerintah Provinsi, setiap provinsi memiliki seorang Gubernur yang diangkat oleh Presiden. Dia bias dipilih kembali tetapi tidak bias menjabat lebih dari dua periode.

Perdana Meteri di Negara Pakistan diangkat oleh Presiden diantara anggota Majelis Nasional, dan harus menujukkan dukungan mayoritas di DPR. Perdana Meteri dibantu oleh Kabinet Federal sebuah dewan menteri yang anggotanya ditunjuk oleh Presiden. Kabinet Federal terdiri dari para menteri ${ }^{15}$.

\section{Legislatif}

Legislatif federal yang bicameral adalah Majilis-i-Shoora (Dewan Penasihat), yang terdiri dari Senat (manjelis tinggi) dan National Majelis

\footnotetext{
14 "Political System and State Structure of Pakistan.," Pakistan Country Profile (CIDOB International Yearbook, 2012), 2.

15 "Political System and State Structure of Pakistan.," 1.

122 Muhammad Faqih \& Ellyda Retpitasari - Konsep Ketatanearaan Pakistan
} 
(majelis rendah). Majelis Nasional memiliki 342 kursi, 272 dari yang dipilih secara first-past-the-post. Kandidat yang memperoleh jumlah suara yang besar dalam satu daerah pemilihan dicalonkan sebagai anggota Majelis Nasional atau Provinsi. Dari 70 kursi sisa, 60 disediakan untuk wanita dan sepuluh untuk minoritas non-muslim, mereka dialokasikan, atas dasar representasi proporsional kepada partai-partai yang memenangkan lebih dari 5\% kursi yang dipilih langsung. Kursi dialokasikan ke masing-masing dari empat provinsi, wilayah kesukuan yang diatus secara federal dan Wilayah Ibukota Islamabad berdasarkan jumlah penduduk. Anggota Majelis Nasional bertugas untuk masa jabatan parlementer dengan masa ketentuan lima tahun, kecuali jika mereka meninggal atau mundur lebih cepat, atau kecuali Majelis Nasional dibubarkan. Senat ialah badan legislatif permanen dengan perwakilan yang sama dari masing-masing empat provinsi, dipilih oleh anggota majelis provinsi masing-masing. Baik Senat maupun Majelis Nasional dapat memulai dan mengesahkan undang-undang kecuali perihal keuangan negara, dimana perhimpunan nasional memiliki kewenangan di atas Senat, secara eksklusif membuat undang-undang tentang masalah uang. Hanya Majelis Nasional yang dapat menyetujui anggaran federal dan Semua hutang piutang keuangan Negara ${ }^{16}$.

\section{Pengadilan Syariat Federal (Yudikatif)}

Mahkamah Agung Pakistan terdiri dari ketua Mahkamah Agung dan tidak lebih dari 16 hakim yang ditunjuk oleh presiden. Untuk bergabung dan dipilih sebagai Mahkamah Agung memiliki pengalaman 5 tahun, atau 15 tahun sebagai advokat dari Pengadilan Tinggi dan memenuhi syarat untuk diangkat sebagai Hakim Mahkamah Agung. Adapun hakim-hakim di pengadilan tinggi provinsi diangkat oleh Presiden setelah berkonsultasi dengan ketua Mahkamah Agung, serta gubernur provinsi dan ketua pengadilan tinggi tempat pengangkatan yang akan dilakukan tersebut ${ }^{17}$.

\section{Hak-Hak Warga Negara}

Pada awal kemerdakaannya, Pakistan merupakan negara yang memiliki beragam masalah hak asasi manusia yang signifikan seperti pembunuhan di luar hukum atau sewenang-wenang oleh pemerintah atau agennya, termasuk pembunuhan di luar hukum, penghilangan paksa, penyiksaan, penahanan sewenang-wenang, campur tangan pemerintah yang sewenang-wenang atau melanggar hukum dengan privasi, bentukbentuk paling buruk dari pembatasan kebebasan berekspresi pers dan

\footnotetext{
16 "Political System and State Structure of Pakistan.," 2-4.

17 "Political System and State Structure of Pakistan.," 3-4.
} 
internet, termasuk kekerasan terhadap jurnalis, penyensoran, dan pemblokiran situs, campur tangan pemerintah yang substansial dengan hak berkumpul secara damai dan kebebasan berserikat, seperti undangundang organisasi non-pemerintah (LSM) yang terlalu ketat, pembatasan kebebasan beragama, pembatasan signifikan atas kebebasan bergerak, tidak korupsi di dalam birokrasi, perdagangan manusia, dan beragama permasalahan yang menyangkut hak warga Negara ${ }^{18}$.

Padahal negara dengan system pemerintahan demokrasi adalah bisa menjamin hak asasi manusianya. HAM sendiri ialah suatu landasan dari keadilan, kebebasan serta kedamaian, sehingga hak asasi manusia dapat mencakup keseluruhan kebutuhan hidup manusia, baik dari segi sipil, politik, sosial, budaya hingga ekonomi. Dtinjau dari segi politik, maka HAM juga bisa digunakan sebagai alat politik suatu negara terhadap negara lainnya. Masyarakat sipil juga bisa menggunakan HAM sebagai alat ukur ketidakadilan dalam kemerdekaan berpendapat daan berfikir yang dialami oleh rakyat kecil pada umumnya ${ }^{19}$. Karena pada prinsipnya HAM menolak keras atas tindakan kesewenang-wenangan pemerintah atau kekuasaan.

Dari adanya beragam masalah hak-hak warga negara, Konstitusi 1973 mengatur pengadilan yang bebas dan independen. Dalam konstitusi 1973 berisikan jamina hak warga negara untuk dilindungi oleh hukum, dan memberlakukan dua kewajiban kepada mereka, kesetiaan kepada negara dan kepatuhan pada hukum. Selain itu, tedapat kebijakan yang memberikan jenis hak fundamental kepada masyarakat seperti hak untuk hidup, kebebasan, persamaan dan kebebasan berbicara, perdagangan dan berserikat.

Seperti yang kita ketahui bahwa negara Pakistan menganut system demokrasi yang mana menurut Robert A. Dahlan dijelaskan setidaknya terdapat lima prinsip mendasar yakni: (1) adanya prinsip persamaan antara masyarakat satu dengan yang lain; (2) adanya peran aktif masyarakat dalam hal pengambilan kebijakan atau keputusan baik secara langsung atau melalu perwakilan di pemerintahan; (3) adanya pemahaman dimana rakyat harus mengerti dan paham terhadap keputusan dan kebijakan yang diambil negara; (4) kontrol sosial yang diinisiasi rakyat, dan memperlihatkan kalua rakyat memiliki kesempatan yang istimewa guna membuat keputusan dan kebijakan yang dilakukan melalui mekanisme dan proses politik dan bisa diterima oleh pihak

18 "Country Reports on Human Rights Practices for 2019, Pakistan 2019 Human Rights Report.," 2.

${ }^{19}$ Muh. Budairi Idjehar, HAM versus Kapitalisme (Yogyakarta: INSIST Press, 2003), 91.

124 Muhammad Faqih \& Ellyda Retpitasari - Konsep Ketatanearaan Pakistan 
manapun; (5) terdapat inclusiveness ialah sebuah pertanda dimana rakyat adalah berdaulat ${ }^{20}$.

Prinsip-prinsip yang dikemukakan oleh Robert A. Dahlan dianggap mampu dalam menjamin keadilan demokrasi ialah rakyat akan mendapatkan persamaan dan perlakuan yang sama di dalam penyelenggaraan negara. Persamaan itulah yang mengindikasikan bahwa semua elemen masyarakat diberikan hak untuk akses dalam pemerintahan.

Adapun pendapat M. Budairi Idjehar bahwa ada 7 kondisi yang akan menjamin masyarakat mendapatkan kesempatan dan kebebasan yaitu:

1. Terdapat kebebasan dalam menginisiasi, membentuk, dan bergabung dalam sebuah organisasi;

2. Adanya kebebasan dalam mengeluarkan pendapat dan/atau pikiran;

3. Terdapat kebebasan dan hak guna memilih dalam pemilihan umum;

4. Diberikan kebebasan untuk menduduki jabatan politik;

5. Ketersediaan sumber informasi alternatif;

6. Adanya hak para pemimpin untuk bersaing dalam memperoleh dukungan dari masyarakat;

7. Menjamin terselenggaranya pemilihan umum yang jujur dan bebas.

Tujuh kondisi di atas akan mengimplikasikan terbukanya ruang partisipasi efektif oleh public dalam penyelenggaraan pemerintahan secara luas. Dengan keterbukaan ruang partisipasi itulah diharapkan dalam pengambilan keputusan dan kebijakan yang menyangkut kehidupan masyarakat tidak bisa dipermainkan atau monopoli.

Bentuk negara, konstitusi, penerapan trias politik, dan hak-hak warga negara mengutamakan prinsip demokrasi namun tetap islami, tentunya hal ini sesuai dengan figh siyasah yang berpedoman pada alQur'an dan Hadits. Adapun dalam Majelis Nasional atau dalam hal ini seperti Dewan Perwakilan Rakyat (DPR) maupun Dewan Perwakilan Rakyat Daerah (DPRD) tetap mengutamakan mayoritas muslim tetapi tetap menghargai dan memberikan toleransi dengan memberikan kursi untuk minoritas non-muslim.

\footnotetext{
${ }^{20}$ Imawati, "Demokrasi di Pakistan Menurut Benazir Bhutto," Al-Adalah: Jurnal Hukum dan Perundingan Islam 5, no. 1 (t.t.): 157.
} 


\section{KESIMPULAN}

Pakistan secara garis besar digambarkan sebagai negara demokrasi yang lemah karena ketidakstabilan sistem pemerintahan dan ketatanegaraan yang ada sejak kemerdakaan negara Pakistan di tahun 1947. Ketidakstabilan ini juga didukung dengan adanya kekerasan dalam beberapa tahun terakhir semakin menguatkan persepsi negatif tentang Pakistan sebagai negara yang tidak kondusif bagi lembaga-lembaga demokrasi. Dalam sejarah terbentuknya negara Islam Pakistan merupakan hasil perjuangan yang cukup Panjang. Hal itu dilatarbelakangi oleh perseteruan antara tiga kekuatan sosial, yaitu Hindu yang menjadi mayoritas di India, kaum muslimin India yang minoritas dan Inggris sebagai penjajah dengan kekuatan politik dan tekhnologi modern yang berkembang di negara Pakistan. Terbentuknya Liga Muslim India, Muhammad Ali Jinnah mencetuskan teori "dua bangsa" dan secara resmi menyampaikan tuntutan sebuah tanah air Muslim yang terpisah dari India. Dalam resolusi tahun 1940 Liga Muslim menyampaikan pembentukan negara Pakistan merdeka dan berdaulat penuh. Dengan berbagai perjuangan yang dilakukan- nya tanggal 15 Agustus 1947 Pakistan lahir sebagai negara berdaulat penuh untuk umat Islam India. Islam dan umat Islam di Pakistan telah memberikan kontribusi secara nyata dalam perkembangan peradaban di dunia Islam. Pakistan merupakan suatu negara yang mengambil Islam sebagai sumber hukum telah menjadi fenomena tersendiri dalam kajian tentang hubungan negara dan agama dalam Islam. 


\section{DAFTAR RUJUKAN}

"Country Reports on Human Rights Practices for 2019, Pakistan 2019 Human Rights Report." United States Departement of State: Bureau of Democracy, Human Rights and Labor, t.t.

Fautanu, Idzam. "Pakistan sebagai Locus Pertarungan Ideologis antara Islam dan Sekularisme (Sebuah Tinjuan Sejarah)." Madrasalah Malam Reboan (MMR), November 2017.

Firdaus, Syam. Pemikiran Politik Barat: Sejarah Filsafat Ideologi, dan pengarubnya terhadap Dunia ke-3. cetakan ke 3. Jakarta: Bumi Aksara, 2007.

Idjehar, Muh. Budairi. HAM versus Kapitalisme. Yogyakarta: INSIST Press, 2003.

Imawati. "Demokrasi di Pakistan Menurut Benazir Bhutto." Al-Adalah: Jurnal Hukum dan Perundingan Islam 5, no. 1 (t.t.).

Jafar, Wahyu Abdul. "FIQH SIYASAH DALAM PERSPEKTIF ALQUR'AN DAN AL-HADIST." AL IMARAH: JURNAL PEMERINTAHAN DAN POLITIK ISLAM 3, no. 1 (1 Juli 2018): 18. https://doi.org/10.29300/imr.v3i1.2140.

Mezzera, Marco, dan Safiya Aftab. "Democratisation and Transitional Justice Cluster "Country Case Study: Pakistan." Pakistan StateSociety Analysis, Initiative for Peacebuilding, 2008.

Mubarok, Muhammad Sofi. "Membedah Anatomi Fiqh Siyasah dalam Putusan Mahkamah Konstitusi tentang Presidential Thershold." Tafaqqub: Jurnal Penelitian dan Kajian Keislaman 8, no. 2 (2020).

Muchlisin. "Pandemi Covid 19 Sebagai Alasan impeacment Presiden Perspektif Hukum Tata Negara." Tafaqqub: Jurnal Penelitian dan Kajian Keislaman 8, no. 2 (2020).

Notosusanto, Nugroho. Norma-Norma dalam Pemikiran dan penulisan Sejarah. Jakarta: Departemen Pertahanan dan Keamanan, 1988.

"Political System and State Structure of Pakistan." Pakistan Country Profile. CIDOB International Yearbook, 2012.

Qazi, Wajahat. "Democratisation and Transitional Justice Cluster "Country Case Study: Pakistan." International Journal of Education and Research 1, no. 1 (Januari 2013).

Zuhri, Syaifudin. "Reformulasi Hukum Perceraian di Pakistan." Jurnal Law and Justice 1, no. 1 (t.t.). 
